\title{
FORMULATION AND OPTIMIZATION OF FLOATING TABLETS OF CLOPIDOGREL BISULPHATE USING DESIGN OF EXPERIMENTS
}

\section{SANJEEVANI S. DESHKAR*, ARVIND S. PAWARA, SATISH V. SHIROLKAR}

\author{
Department of Pharmaceutics, Dr. D. Y. Patil Institute of Pharmaceutical Sciences and Research, Pimpri, Pune, India 411018 \\ Email: sanjeevanisd@yahoo.com
}

Received: 10 Jun 2018, Revised and Accepted: 04 Sep 2018

\begin{abstract}
Objective: The present study aimed at designing of floating matrix tablet of clopidogrel bisulphate by design of experiments.

Methods: The tablets were prepared by direct compression technique using hydroxypropyl methylcellulose K15 (HPMC) as a matrix polymer and sodium bicarbonate as a gas generating agent. In order to optimize the concentration of HPMC $\left(\mathrm{X}_{1}\right)$ and sodium bicarbonate $\left(\mathrm{X}_{2}\right)$, a $3^{2}$ full factorial design was employed. The tablet formulations were evaluated for floating lag time ( $\left.\mathrm{Y}_{1}\right)$, floating or buoyancy time ( $\left.\mathrm{Y}_{2}\right)$, percent water uptake, and differential scanning calorimetry (DSC) and in vitro drug release ( $\left.\mathrm{Y}_{3}\right)$.

Results: The formulation variables, HPMC concentration, and sodium bicarbonate concentration exerted a significant effect on floating behavior and drug release characteristics of the tablet. The optimized formulation, with $15 \%$ sodium bicarbonate concentration and $30 \%$ HPMC concentration resulted in $5 \pm 2.6 \mathrm{sec}$ of floating lag time, $22.0 \pm 0.6 \mathrm{~h}$ of floating time and $42.0 \pm 0.99 \%$ of clopidogrel bisulphate release in $8 \mathrm{~h}$ of dissolution study. The drug release mechanism was identified as nonfickian. The water uptake studies revealed that with an increase in HPMC concentration, there was an increase in swelling index of tablet whereas higher sodium bicarbonate concentration supported the faster erosion of matrix tablets. DSC study revealed no interaction of drug and polymers. The lower percentage error between predicted and observed responses of the optimized formulation validated the design.
\end{abstract}

Conclusion: The study demonstrated successful designing of floating clopidogrel bisulphate tablet with factorial design.

Keywords: Clopidogrel bisulphate, Antiplatelet drug, Floating tablet, Design of experiment, Factorial design, Gastroretentive drug delivery

(C) 2018 The Authors. Published by Innovare Academic Sciences Pvt Ltd. This is an open access article under the CC BY license (http://creativecommons.org/licenses/by/4.0/) DOI: http://dx.doi.org/10.22159/ijap.2018v10i6.27873

\section{INTRODUCTION}

Platelet aggregation has a major role in the clotting process and thrombosis [1]. Platelet hyper-reactivity in atherosclerosis and inflammatory disorders may result in serious conditions like acute coronary syndromes, increasing incidences of thrombosis and vascular occlusion [2]. The coronary events may lead to cardiovascular diseases (CVD), brain ischemia, peripheral arterial disease and other hemorrhagic disorders [3] and are the major causes of mortality and morbidity. Coronary artery disease (CAD) is a major cause of critical illness and amongst the top five causes of death in Indian population [4]. In India, almost $24.8 \%$ of all deaths are due to CAD and CVD, and $52 \%$ of deaths occur before the age of 70. This has resulted in high social and economic burden [5].

The importance of antiplatelet therapy in the treatment and prevention of atherothrombosis is well established. Each antiplatelet agents have a different mechanism of action and mostly interfere with one or more steps of thrombus formation including platelet release, adhesion, activation, and aggregation [6]. One of the most commonly used antiplatelet drugs is aspirin that exerts its action by inhibition of cyclooxygenase enzyme and reduction of thromboxane A2 levels. However, due to the lower efficacy of aspirin in reducing ischemic events, most of the clinical research currently is focused on clopidogrel therapy [7].

Clopidogrel is a second generation thienopyridine commonly used in broad spectrum therapy of acute coronary syndromes. Its antiplatelet activity is the result of selective inhibition of ADP binding to the platelet receptor preventing ADP-mediated platelet responses [8]. Clopidogrel is a prodrug that transforms into active drug after biotransformation in the liver. Various clinical trials have demonstrated the safety and efficacy of clopidogrel ineffective treatment of peripheral artery disease [9]. Although not completely understood, the variability in the antiplatelet effect of clopidogrel is attributed to its variable gastrointestinal absorption which is a result of low solubility [10]. The solubility of clopidogrel is mainly reported to be $\mathrm{pH}$ dependent, showing higher solubility in acidic $\mathrm{pH}$ and solubility drops when $\mathrm{pH}$ increases above 3.0 [11]. Taking this into account, a gastroretentive drug delivery system, releasing the maximum drug in acidic stomach $\mathrm{pH}$ would be desirable.

Gastroretentive drug delivery is suitable for drugs that have a solubility in acidic $\mathrm{pH}$, absorption window in the upper small intestinal region or act locally. Out of the various approaches used for gastro retention, the floating drug delivery system appears to be the most promising one $[12,13]$. The floating systems that have been previously reported are tablets, beads, microspheres, pellets, etc., out of which tablets are easiest and simplest to manufacture [14-16]. In one of our previous study, we designed an immediate release pellet formulation of clopidogrel bisulphate [17]. In the present study, a floating matrix gastroretentive tablet of clopidogrel bisulphate was attempted. The formulation was designed using $3^{2}$ full factorial design in order to optimize formulation variables. The prepared tablets were evaluated for in vitro characteristics.

\section{MATERIALS AND METHODS}

Clopidogrel bisulphate was obtained as gift sample from Sava Healthcare, Pune, India. HPMC K15 was obtained from Colorcon, India. All the chemicals and solvents were of analytical grade.

\section{Drug-excipient compatibility study}

During the formulation of tablets, there are chances of drug degradation as well as unstable product formation due to drugexcipient chemical interactions. Hence, drug and excipient compatibility study is required. Preformulation studies were conducted with various commonly used excipients at $40{ }^{\circ} \mathrm{C} \pm 2$ ${ }^{\circ} \mathrm{C} / 75 \% \pm 5 \% \mathrm{RH}$ and $30{ }^{\circ} \mathrm{C} \pm 2{ }^{\circ} \mathrm{C} / 65 \% \pm 5 \% \mathrm{RH}$. The drug, along with different excipients, in 1:1 ratio was mixed, sealed in clear glass vials with LDPE stoppers, which were then charged into stability chambers (Remi, CHM 16, India) at the above-mentioned conditions. The vials were inspected periodically to observe physical changes and discoloration. For comparison of physical changes and discoloration, initial samples were used as reference sample. The physical observation was done after one month. At the end of one 
month, the samples were analyzed by FTIR (Shimadzu, 8400S, Japan) to observe any chemical changes in the blend.

\section{Formulation of clopidogrel bisulphate floating tablets}

Clopidogrel bisulphate, polymers, and excipients were mixed thoroughly and passed though sieve 60 . The tablets with different composition (table 1) were prepared by direct compression technique on a rotary punch tablet compression machine (Rimek mini press, MT-II, India). The powder was weighed and individually filled in the die cavity (10 $\mathrm{mm}$ diameter), and constant pressure was applied. The tablets were evaluated for various parameters like thickness, average weight, hardness, drug content, floating lag time, floating time, water uptake studies and in vitro drug release.

\section{Optimization using a factorial design}

After initial trials of floating tablets, the concentration of sodium bicarbonate and HPMC K15 were identified as high-risk formulation variables. In order to optimize the levels of these two variables, a $3^{2}$ full factorial design was applied. The design consisted of two independent variables with three levels resulting in 9 experimental runs (table 1). The first independent variable was HPMC K15 concentration (X1) at levels 20,30 and $40 \% \mathrm{w} / \mathrm{w}$ and the other independent variable was sodium bicarbonate concentration (X2) at levels 5,10 and $15 \% \mathrm{w} / \mathrm{w}$.

The effect of these variables on responses, floating lag time (Y1) and drug release after $8 \mathrm{~h}(\mathrm{Y} 2)$ was evaluated. The resulting data were fitted into design expert software (Design Expert, version 10, Stat-ease, USA) and analyzed statistically. The multiple linear regression analysis was done to study the effect of variables on the responses. The statistical significance of the data was established using analysis of variance (ANOVA).

The surface response and contour plots were generated to study the interactive effects of the variables.

Table 1: $3^{2}$ factorial design for optimization of clopidogrel bisulphate tablets

\begin{tabular}{|c|c|c|c|c|c|c|c|c|c|}
\hline Ingredient (mg) & F1 & F2 & F3 & F4 & F5 & F6 & F7 & F8 & F9 \\
\hline Clopidogrel bisulphate & 98 & 98 & 98 & 98 & 98 & 98 & 98 & 98 & 98 \\
\hline HPMC K15M $\left(\mathrm{X}_{1}\right)^{*}$ & $60(20 \%)$ & $90(30 \%)$ & $120(40 \%)$ & $60(20 \%)$ & $90(30 \%)$ & $120(20 \%)$ & $40(20 \%)$ & $90(30 \%)$ & $120(40 \%)$ \\
\hline Sodium bicarbonate $\left(\mathrm{X}_{2}\right)^{*}$ & $15(5 \%)$ & $15(5 \%)$ & $15(5 \%)$ & $30(10 \%)$ & $30(10 \%)$ & $30(10 \%)$ & $45(15 \%)$ & $45(15 \%)$ & $45(15 \%)$ \\
\hline Avicel PH 101 & 121 & 91 & 61 & 106 & 76 & 46 & 91 & 61 & 31 \\
\hline Talc & 3 & 3 & 3 & 3 & 3 & 3 & 3 & 3 & 3 \\
\hline Magnesium stearate & 3 & 3 & 3 & 3 & 3 & 3 & 3 & 3 & 3 \\
\hline Total weight (mg) & 300 & 300 & 300 & 300 & 300 & 300 & 300 & 300 & 300 \\
\hline
\end{tabular}

*values in the bracket indicate a concentration in percentage of the total tablet weight

\section{Evaluation of tablets}

\section{Thickness, average weight, and hardness}

The thickness of tablets was determined using a vernier caliper. Hardness of tablets was determined using a Monsanto hardness tester. Twenty tablets of each formulation were weighed using electronic balance, and average tablet weight was calculated.

\section{Drug content}

Three tablets from each formulation were triturated in mortar and pestle. Powder equivalent to $75 \mathrm{mg}$ of clopidogrel was weighed and dispersed into $20 \mathrm{ml}$ of methanol and sonicated for $15 \mathrm{~min}$. The volume was made with a hydrochloric acid buffer solution $\mathrm{pH}$ 2.0. The resultant solution was then filtered through a $0.45 \mu$ filter and further diluted with the same buffer solution. Drug content was spectrophotometrically determined at $240 \mathrm{~nm}$ (Shimadzu, UV 1700, Japan). The mean of three determinations was calculated.

\section{Floating lag time and total floating time}

Floating lag time and total floating time of tablets was determined using a method by Gharti et al. [18]. The tablets were placed in a USP type II dissolution test apparatus containing $900 \mathrm{ml}$ of $\mathrm{pH} 2.0$ hydrochloric acid buffer solution at $37 \pm 0.5^{\circ} \mathrm{C}$ and $50 \mathrm{rpm}$. The time required for the tablet to rise to the surface of the dissolution media and total time for which the tablets remained at the surface were noted as floating lag time and total floating time respectively.

\section{Swelling study}

The swelling study of clopidogrel bisulfate tablets was conducted in order to study polymer swelling and rate of test medium uptake by tablets. The preweighed tablets were placed in a USP type II dissolution test apparatus. The test medium used was $\mathrm{pH} 2.0$ hydrochloric acid buffer solution maintained at $37 \pm 0.5{ }^{\circ} \mathrm{C}$ and 50 $\mathrm{rpm}$. At regular intervals viz., 1, 2, 3, 4, 5, 6, 7 and $8 \mathrm{~h}$, tablets were removed from the dissolution media, lightly blotted with tissue paper to remove excess dissolution fluid and weighed [19].

The percentage water uptake was estimated for each time point using the following formula.
Percent water uptake

$$
=\frac{\text { (weight of swollen tablet matrix }- \text { initial weight of tablet })}{\text { initial weight of tablet }} \times 10
$$

\section{Differential scanning calorimetry}

The DSC measurement of the drug, physical mixture and tablet formulation was performed on a differential Scanning calorimeter (Shimadzu, DSC 60, Japan) with the thermal analyzer. All accurately weighed samples $(5 \mathrm{mg})$ were placed in sealed aluminum pans, before heating under nitrogen flow $(10 \mathrm{ml} / \mathrm{min})$ at a scanning rate of $10^{\circ} \mathrm{C} / \mathrm{min}$ from $35^{\circ} \mathrm{C}-300^{\circ} \mathrm{C}$.

\section{Drug release studies}

In order to check drug release profiles and dissolution kinetics, drug release studies of tablet formulations were conducted using USP apparatus II. The conditions of dissolution were as per USP XXIII monograph with $900 \mathrm{ml}$ of hydrochloric acid buffer $(\mathrm{pH}$ $2.0)$ solution as dissolution media. The speed of rotation was 50 $\mathrm{rpm}$, and the temperature was maintained at $37 \pm 0.5^{\circ} \mathrm{C}$. Aliquots of the sample were withdrawn after every 1 hour, and the study was continued up to $8 \mathrm{~h}$. Withdrawn samples were filtered, diluted appropriately and analyzed on a UV spectrophotometer at $240.0 \mathrm{~nm}$ using dissolution medium as a blank. An equivalent volume of fresh dissolution medium was added to compensate for the loss due to sampling. The experiment was performed in triplicate and results were expressed as mean values with standard deviation. In order to study the mechanism of drug release, the data of dissolution was fitted to different kinetics model, viz. zero order, first order, Higuchi matrix, KorsemayarPeppas and Hixson-Crowell [20].

\section{RESULT AND DISCUSSION}

\section{Drug-excipient compatibility study}

Drug-excipient compatibility was assessed through FTIR analysis of mixtures of excipients and drug substances in the solid state. From the physical observations of the blends, no significant physical changes in colour or appearance were observed at $40{ }^{\circ} \mathrm{C} \pm 2{ }^{\circ} \mathrm{C} /$ $75 \% \pm 5 \% \mathrm{RH}$ and $30{ }^{\circ} \mathrm{C} \pm 2{ }^{\circ} \mathrm{C} / 65 \% \pm 5 \% \mathrm{RH}$ as compared to initial. 
FTIR spectrum of clopidogrel bisulfate shows major peaks at 3389.0 for $-\mathrm{N}-\mathrm{H}$ stretch, 2534.5 for $-\mathrm{SH}, 1751.4 \mathrm{~cm}^{-1}$ for $-\mathrm{C}=0$ stretch and 783.1 for-C-Cl stretch (fig. 1). The similar peaks at characteristic wave numbers were observed in the physical mixture of drug and excipients. This indicated the absence of any interaction and compatibility of drug and excipient.
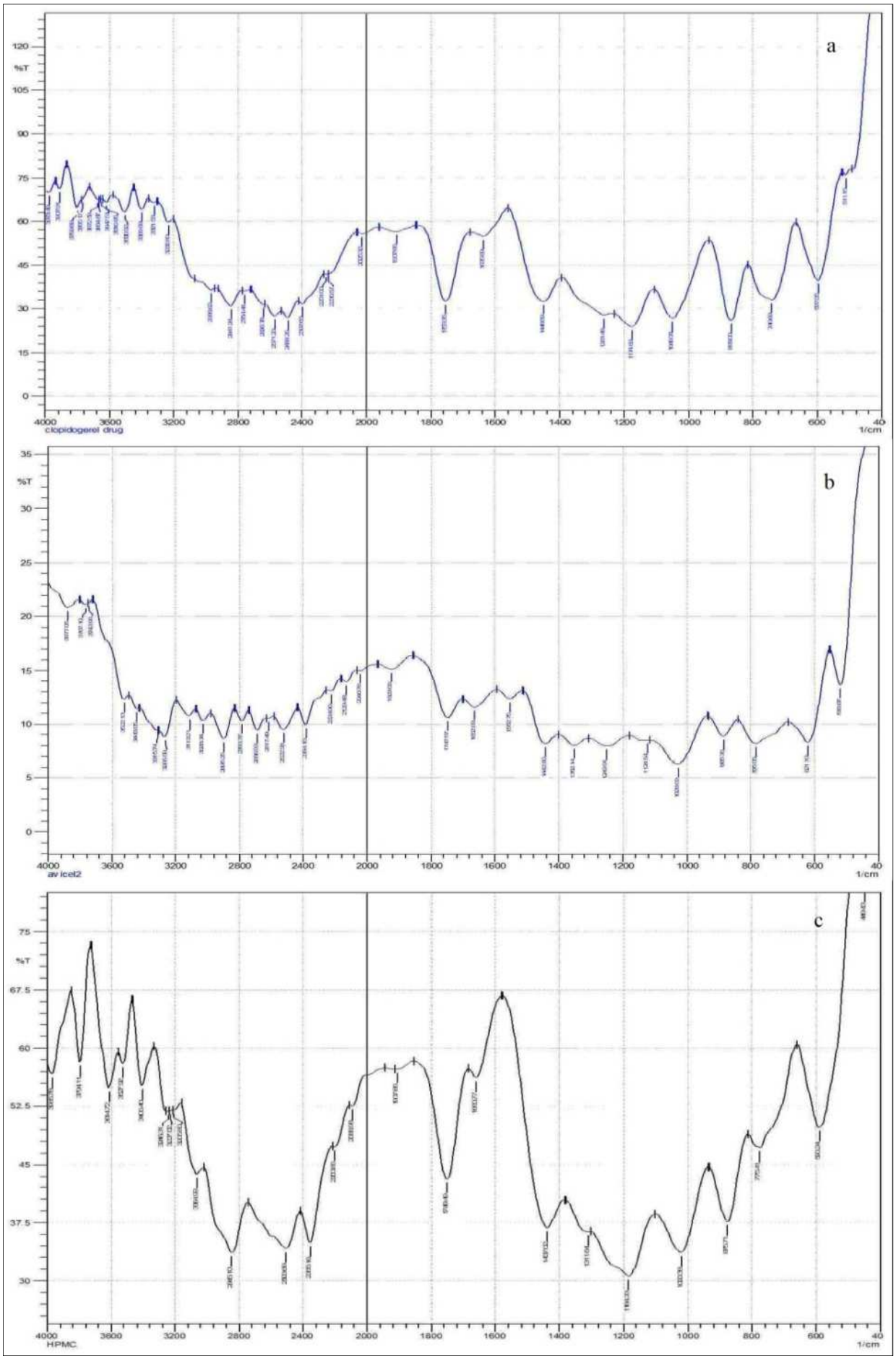

Fig. 1: FTIR spectra of (a) clopidogrel bisulphate (b) clopidogrel bisulphate and avicel mixture (c) clopidogrel bisulphate and HPMC K15 mixture

\section{Optimization of tablet formulations using a factorial design}

In a sustained release floating tablet, the concentration of gas generating agent, sodium bicarbonate and type and concentration of swelling polymer are critical formulation variables. In literature, the use of HPMC as a swellable polymer in the formulation of sustained release floating tablet has been suggested [18]. Considering the low solubility of clopidogrel bisulphate, HPMC K15 grade with viscosity of 10000 to $15000 \mathrm{mPa}$. s was selected as the polymer in the present study. In order to systematically evaluate the effect of concentration of HPMC $\mathrm{K} 15\left(\mathrm{X}_{1}\right)$ and sodium bicarbonate $\left(\mathrm{X}_{2}\right)$ on properties of floating tablet, a $3^{2}$ full factorial design was applied. The results of independent variables on key responses, floating lag time $\left(\mathrm{Y}_{1}\right)$, floating time $\left(\mathrm{Y}_{2}\right)$ and drug release in $8 \mathrm{~h}\left(\mathrm{Y}_{3}\right)$ is depicted in table 2 .

The hardness of the tablets was found in the range of 5.0 to $6.3 \mathrm{~kg} / \mathrm{cm}^{2}$. The weights of tablets were within the weight variation limits as per USP. The lower values of friability indicate that tablets are resistant to 
mechanical shocks. The drug content of tablet formulation was found in the range $91.21 \pm 1.15$ to $97.12 \pm 2.64 \%$. The floating lag time was found in the range of $3 \pm 1.0$ to $69 \pm 5.5 \mathrm{sec}$ and total floating or buoyancy time was in the range of $9.0 \pm 0.0$ to $22.0 \pm 0.6 \mathrm{~h}$.

Table 2: Evaluation parameters for floating tablet of clopidogrel bisulphate

\begin{tabular}{|c|c|c|c|c|c|c|c|c|}
\hline Formulation & $\begin{array}{l}\text { Friability } \\
(\%)^{* *}\end{array}$ & $\begin{array}{l}\text { Hardness } \\
\left(\mathrm{Kg} / \mathrm{cm}^{2}\right)^{*}\end{array}$ & $\begin{array}{l}\text { Thickness } \\
\text { (mm) \# }\end{array}$ & $\begin{array}{l}\text { Average } \\
\text { weight \# (mg) }\end{array}$ & $\begin{array}{l}\text { Drug } \\
\text { content* } \\
(\%)\end{array}$ & 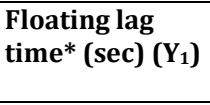 & $\begin{array}{l}\text { Floating } \\
\text { time* (h) } \\
\left(\mathrm{Y}_{2}\right)\end{array}$ & $\begin{array}{l}\text { Drug release in } \\
8 \mathrm{~h}(\%)^{*} \\
\left(\mathrm{Y}_{3}\right)\end{array}$ \\
\hline $\mathrm{F} 1$ & 0.14 & $5.0 \pm 2$ & $5 \pm 2$ & $294.6 \pm 2.5$ & $97.12 \pm 2.64$ & $34 \pm 1.0$ & $16.3 \pm 0.6$ & $67.7 \pm 1.23$ \\
\hline F2 & 0.19 & $5.1 \pm 1.6$ & $4 \pm 1$ & $294.0 \pm 2.5$ & $96.94 \pm 2.65$ & $41 \pm 0.5$ & $18.3 \pm 0.0$ & $43.9 \pm 1.63$ \\
\hline F3 & 0.20 & $5.5 \pm 1.6$ & $5 \pm 1$ & $292.3 \pm 3.2$ & $95.57 \pm 2$ & $54 \pm 0.5$ & $21.3 \pm 0.6$ & $37.0 \pm 1.26$ \\
\hline $\mathrm{F} 4$ & 0.33 & $5.0 \pm 0.6$ & $5 \pm 0.5$ & $293.3 \pm 2.6$ & $94.47 \pm 1.52$ & $4 \pm 1.1$ & $9.0 \pm 0.0$ & $66.0 \pm 0.45$ \\
\hline F5 & 0.33 & $6.1 \pm 0.6$ & $5 \pm 0$ & $291.6 \pm 5.5$ & $95.08 \pm 3.05$ & $12 \pm 0.5$ & $20.3 \pm 0.6$ & $38.4 \pm 3.57$ \\
\hline F6 & 0.40 & $6.3 \pm 0.2$ & $4 \pm 1$ & $292.6 \pm 1.7$ & $93.43 \pm 2.05$ & $69 \pm 2.0$ & $20.0 \pm 1.7$ & $32.4 \pm 0.57$ \\
\hline F7 & 0.36 & $6.3 \pm 0.4$ & $5 \pm 1$ & $294.0 \pm 3.5$ & $92.22 \pm 1.15$ & $3 \pm 5.5$ & $13.3 \pm 0.6$ & $67.9 \pm 1.40$ \\
\hline F8 & 0.33 & $6.3 \pm 0.8$ & $5 \pm 1.5$ & $292.3 \pm 4.0$ & $91.21 \pm 1.15$ & $5 \pm 2.6$ & $22.0 \pm 0.6$ & $42.0 \pm 0.99$ \\
\hline F9 & 0.26 & $6.1 \pm 1.4$ & $5 \pm 2$ & $295.0 \pm 2.0$ & $91.74 \pm 1.52$ & $7 \pm 3.0$ & $22.0 \pm 0.6$ & $33.4 \pm 0.89$ \\
\hline
\end{tabular}

mean $\pm \mathrm{SD} * \mathrm{n}=3,{ }^{* *} \mathrm{n}=10, \# \mathrm{n}=20$

The response data was fitted to linear regression analysis and equations, 1, 2 and 3 were obtained.

Floating lag time $\left(\mathrm{Y}_{1}\right)=+25.44+14.83 \mathrm{X}_{1}-19.00 \mathrm{X}_{2}-4.00 \mathrm{X}_{1} \mathrm{X}_{2 \ldots \ldots \ldots \ldots . .1}$

Floating time $\left(\mathrm{Y}_{2}\right)=+18.09+4.17 \mathrm{X}_{1}+0.23 \mathrm{X}_{2}+0.92 \mathrm{X}_{1} \mathrm{X}_{2} \ldots \ldots \ldots \ldots \ldots \ldots \ldots . . . . . .2$

Drug release $\left(\mathrm{Y}_{3}\right)=+47.63-16.47 \mathrm{X}_{1}-0.88 \mathrm{X}_{2}-0.95 \mathrm{X}_{1} \mathrm{X}_{2} \ldots \ldots \ldots \ldots \ldots \ldots \ldots \ldots . . . . . . . . .3$

In equation 1 , the positive coefficient of $X_{1}$ indicated an increase in floating lag time with an increase in HPMC concentration and a negative coefficient of $\mathrm{X}_{2}$ indicated a decrease in floating lag time with an increase in sodium bicarbonate concentration. The presence of interactive term indicated the interactive effect of both the variables on the response.

For floating time, equation 2 was obtained in which the coefficients of $\mathrm{X}_{1}$ and $\mathrm{X}_{2}$ were positive. The increase in sodium bicarbonate concentration, as well as HPMC concentration, would result in an increase in floating time.

Equation 3 presented the effect of $X_{1}$ and $X_{2}$ on response $Y 3$ that is drug release after $8 \mathrm{~h}$. Negative coefficient of $X_{1}$ indicated a decrease in drug release after increase in HPMC concentration and increase in sodium bicarbonate concentration also decreased drug release.

These effects can be further explained by response plots generated using regression data. These plots are shown in fig. 2, 3 and 4.

\section{Effect on floating lag time}

The response surface plot (fig. 2) demonstrated the effect of HPMC concentration $\left(\mathrm{X}_{1}\right)$ and sodium bicarbonate concentration $\left(\mathrm{X}_{2}\right)$ on floating lag time. A significant decrease in floating lag time was observed with an increase in sodium bicarbonate concentration. At $20 \%$ HPMC ( -1 level) concentration, floating lag time decreased from $34 \mathrm{sec}$ to $3 \mathrm{sec}$ with increase in sodium bicarbonate concentration from $5 \%$ to $15 \%$. As sodium bicarbonate is a gas generating agent, higher concentration of sodium bicarbonate accelerates the formation of carbon dioxide that gets entrapped in the gel layer of swollen tablet matrix altering the density of the tablet. This results in floating of the tablet. With the increase in HPMC concentration, there was an increase in floating lag time. This increase in lag time could be attributed to lag time in the wetting of HPMC matrix due to its higher concentration.

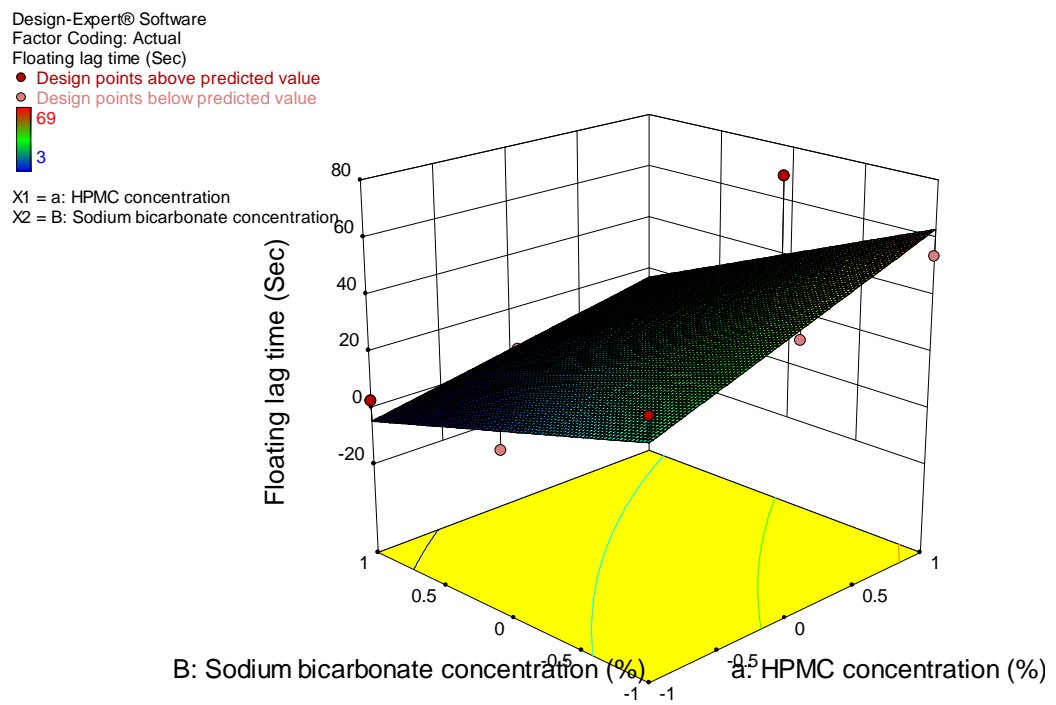

Fig. 2: Surface response plot showing influence of HPMC and sodium bicarbonate concentration on floating lag time

\section{Effect on floating time}

Fig. 3 demonstrates the effect of HPMC concentration and sodium bicarbonate concentration on floating time. There is no significant effect of sodium bicarbonate concentration on floating time. With the increase in HPMC concentration, there was increase in floating time of tablet formulation. Higher concentration of polymer resulted in viscous gel matrix that 
aided in entrapment of released carbon dioxide in tablet matrix. This helped in floating of the tablet for a prolonged duration. The surface plot indicates that at highest level of HPMC, the floating time is more than $22 \mathrm{~h}$.

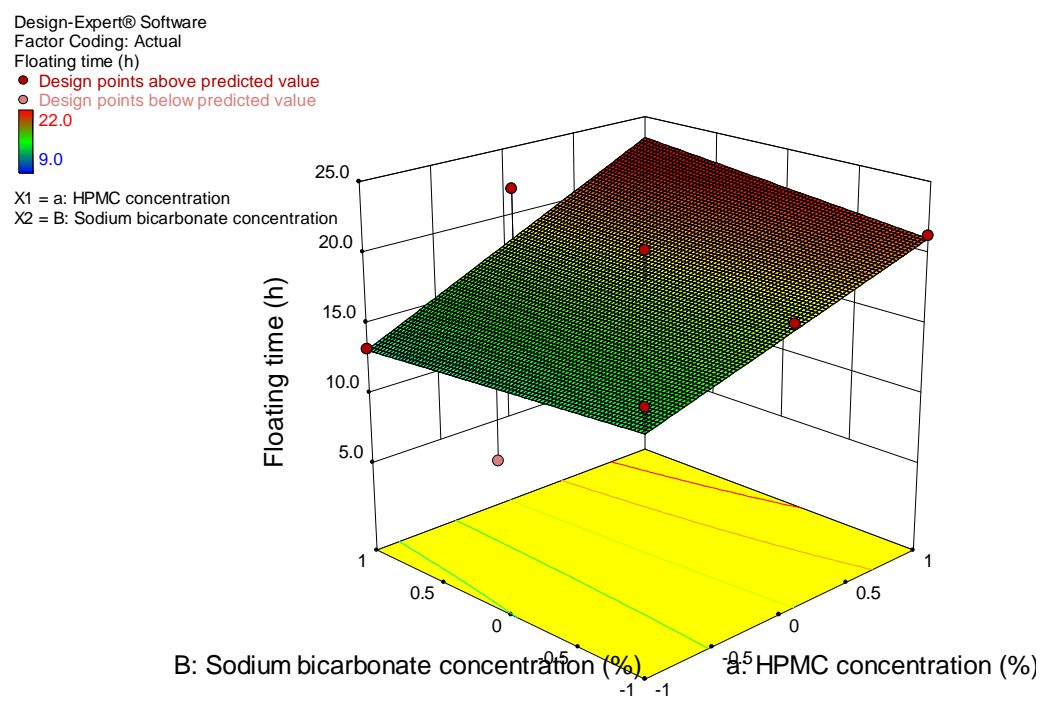

Fig. 3: Surface response plot showing influence of HPMC and sodium bicarbonate concentration on floating time

\section{Effect on drug release}

The drug release was found to be dependant on HPMC concentration (fig. 4). There was no significant effect of sodium bicarbonate concentration on the release of the drug. Increase in polymer concentration from $20 \%$ to $40 \%$ of tablet weight decreased the drug release from $66.0 \pm 0.45$ to $32.4 \pm 0.57 \%$ at the middle level of sodium bicarbonate (F4 to F6). This decrease in drug release could be attributed to increase in thickness of swollen polymer gel layer acting as a barrier for drug diffusion.

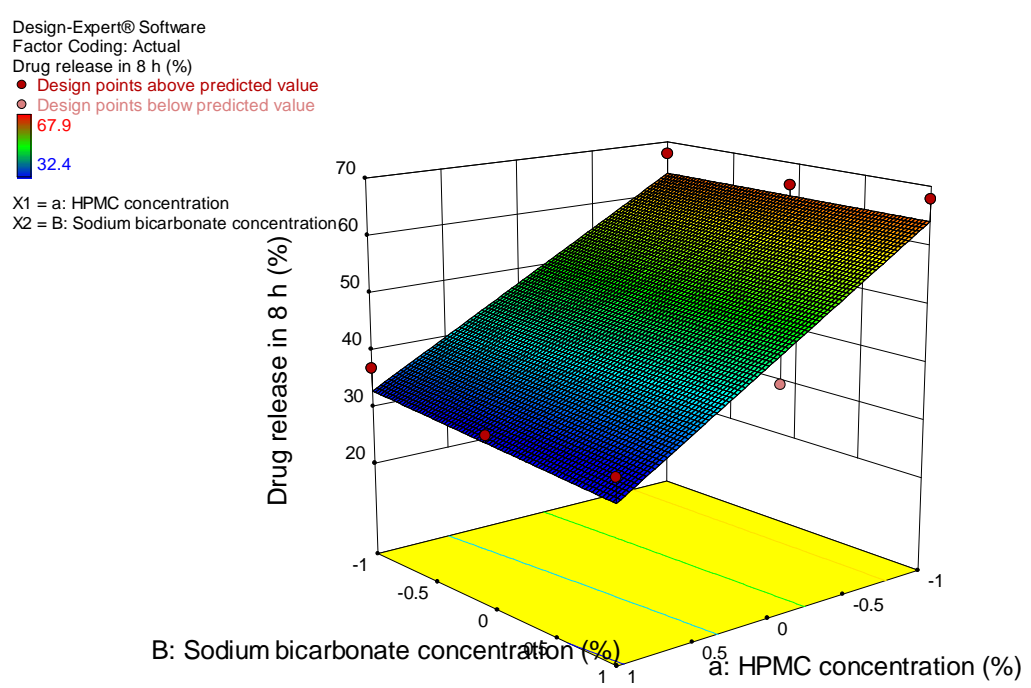

Fig. 4: Surface response plot showing the influence of HPMC and sodium bicarbonate concentration on drug release in $8 \mathrm{~h}$

\section{Water uptake studies}

Hydrophilic polymers have been well known to retard the drug release by swelling in aqueous media. In general, because the drug core of polymer tablets is glassy, the drug cannot diffuse unless swelling takes place. On swelling drug molecules dissolve in water and are released by diffusion. The process of swelling, erosion and drug release can occur simultaneously and are interconnected. An ability of polymers to retard the drug release rate is related to its viscosity. During swelling of the polymer the macromolecular chains absorb water, leading to an expansion of the network formed and formation of a quasi-equilibrium structure. This network structure usually is held together by physical chain entanglements, hydrogen bond, tie junctions produced by various types of forces. Upon further absorption of water, these gels may start disentangling, indicating a competitive phenomenon of swelling and dissolution.

Fig. 5 shows the water uptake (\%) by floating sustained release matrix tablets of clopidogrel bisulphate. It is evident that HPMC K15 undergoes hydration as soon as it comes in contact with the medium. As the concentration of polymer was increased, the percent water uptake was more. Visual observation showed that all polymer matrices appeared swollen almost from the beginning and a viscous gel mass was produced. In the case of lower polymer concentrations (20 and $30 \%$ ), there was a significant increase in tablet weight in the 
initial dissolution stage. But further, there was a decrease in the tablet weight. This could be due to the reaction of sodium bicarbonate to release carbon dioxide and simultaneous release of drug resulting in substantial erosion of tablet matrix at lower polymer concentrations.

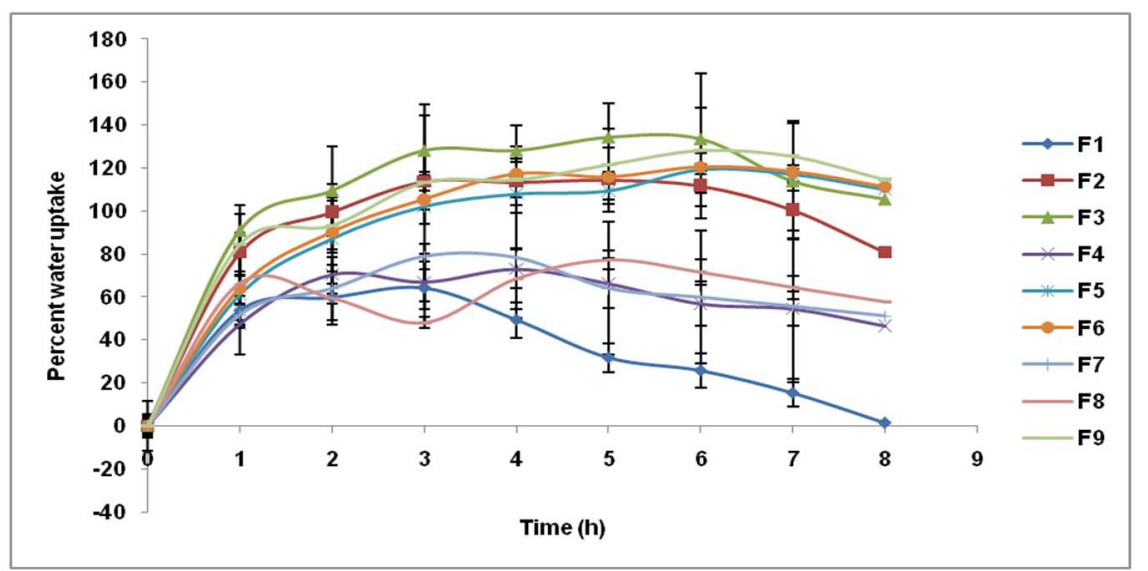

Fig. 5: Percent water uptake by floating clopidogrel bisulphate tablets *mean \pm SD, n=3

\section{Differential scanning calorimetry}

In order to observe the changes occurred in the clopidogrel bisulphate during tablet formulation, DSC study was conducted. Fig. 6 indicates DSC of clopidogrel bisulphate, its physical mixture with excipients and formulation of tablet. DSC graph of pure drug, clopidogrel bisulphate revealed an endotherm at $174{ }^{\circ} \mathrm{C}$ which indicates the melting point of clopidogrel bisulphate. The sharpness of the endotherm revealed crystalline nature of the drug. The physical mixture of drug and excipients demonstrated broad endotherm of the drug at $174{ }^{\circ} \mathrm{C}$ followed by another broad endotherm at 180 to $205{ }^{\circ} \mathrm{C}$. Similar DSC graph was observed for formulation. This could be because of the glass transition temperature of HPMC K15 in the range of 170 to 190 ${ }^{\circ} \mathrm{C}$. As the melting point of the drug lies in the same range, there is overlapping of endotherm of clopidogrel bisulphate and HPMC K15 resulting in broadening of drug endotherm. There was no significant difference was observed in DSC curve of physical mixture and formulation indicating absence of any change or interaction between drug and excipients.

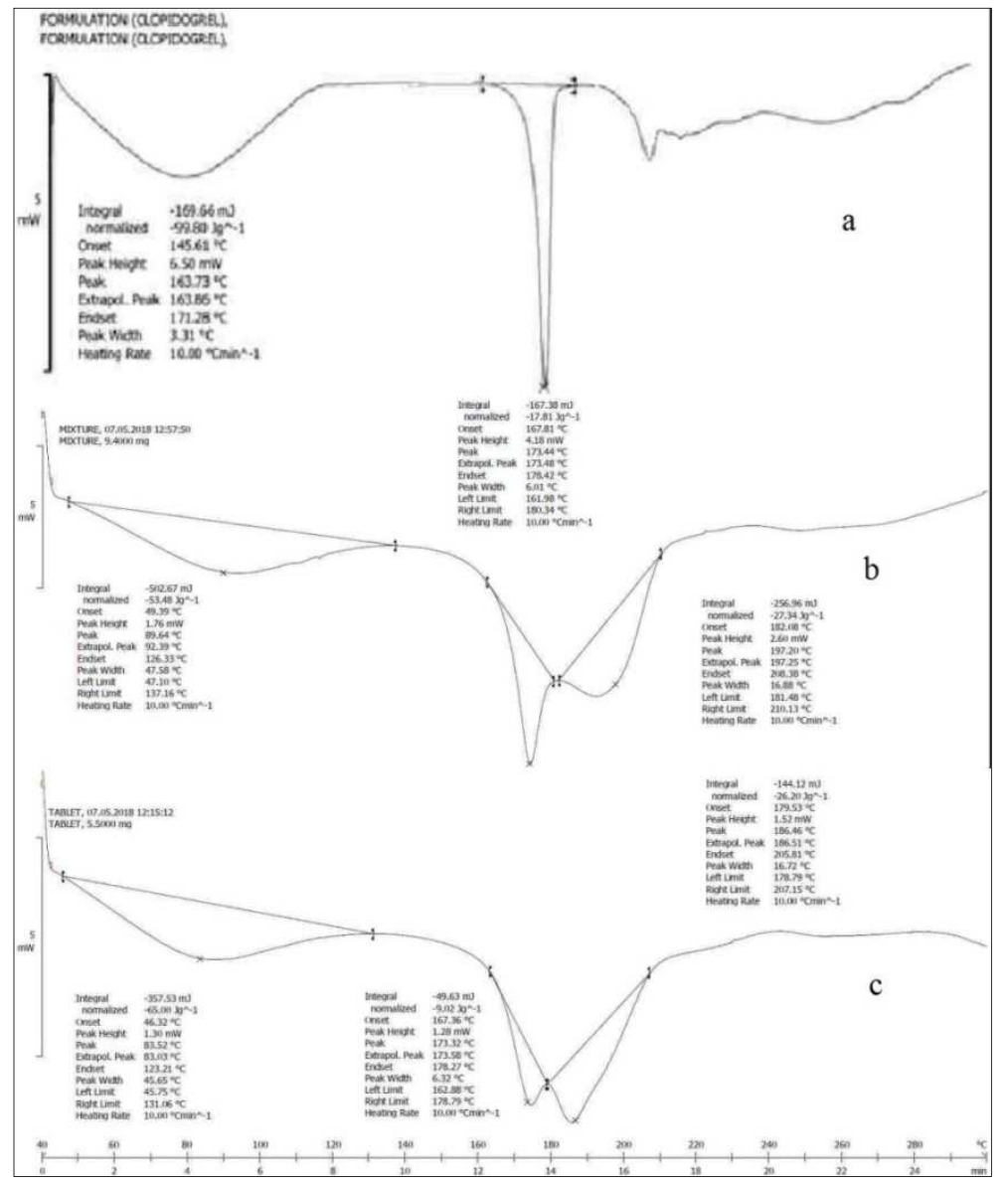

Fig. 6: DSC of (a) clopidogrel bisulphate (b) a physical mixture of drug and excipients (c) tablet formulation F8 


\section{In vitro drug release profile}

Fig. 7 indicates the drug release profile for all the nine tablet formulations. All the nine formulations showed sustained drug release over $8 \mathrm{~h}$ of dissolution. The drug release was found in the range of $32.4 \pm 0.57$ to $67.9 \pm 1.40 \%$ in $8 \mathrm{~h}$ of dissolution. These results are different from the study by Rao et al.[21], where the authors reported more than $80 \%$ of clopidogrel bisulfate release in $8 \mathrm{~h}$ of dissolution. These results could be due to different excipients used in the composition of tablet and different dissolution media. As the solubility of clopidogrel bisulphate is highly $\mathrm{pH}$ dependant, change in the $\mathrm{pH}$ of dissolution of media would result in change in the dissolution profile.

For 20\% (F1, F4, and F7) and 30\% (F2 and F8) cocentration of HPMC, a biphasic release pattern was observed. There was a burst release followed by sustained release of the drug. The burst release observed during first half hour of dissolution could be due to the initial lag time required for hydration of polymer and thus, the formation of gel layer. Hence, the surface bound drug was immediately released. Further swelling of polymer matrix provides a diffusional barrier allowing sustained release of the drug. On the physical evaluation of tablets during dissolution study, it was found that tablets swell initially and form a strong viscous gel on contact with the dissolution medium.

Fig. 8 shows the effect of HPMC concentration on in vitro drug release. With the increase in polymer concentration, the initial burst release of drug as well as the overall drug release was decreased. The increase in polymer concentration allows quicker hydration of polymer and lower exposure of drug to dissolution media. The viscosity of the gel matrix also increases at higher polymer concentration.

The data obtained from the release profile of floating sustained release matrix tablets of clopidogrel bisulphate was introduced to various mathematical models using PCP Disso software to ascertain the mechanism of drug release from the tablet.

The kinetic values obtained from various mathematical models are shown in table 3.

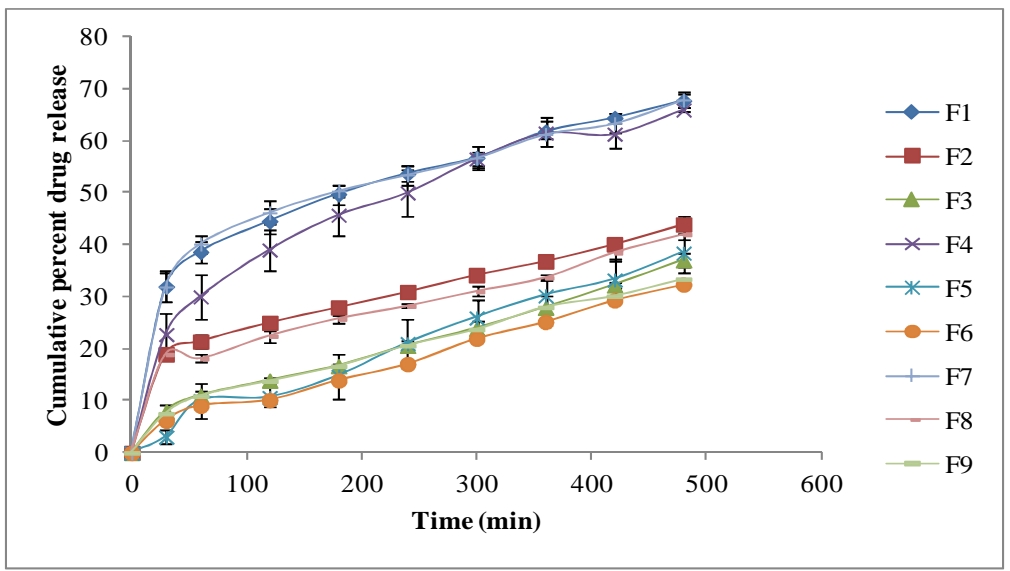

Fig. 7: In vitro drug release profile of clopidogrel bisulphate floating tablet formulations, ${ }^{*}$ mean $\pm S D, n=3$

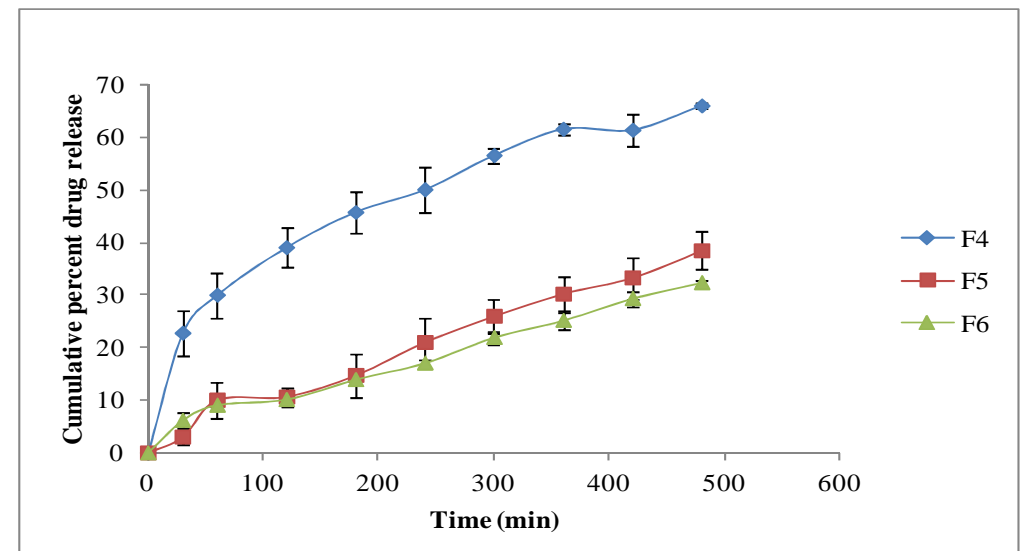

Fig. 8: Effect of HPMC cocentration on in vitro drug release. $(20 \%, 30 \%, 40 \%)$, *mean $\pm S D, n=3$

Table 3: Kinetic values of drug release data for clopidogrel bisulphate tablets

\begin{tabular}{|c|c|c|c|c|c|c|c|}
\hline \multirow{2}{*}{$\begin{array}{l}\text { Formulation } \\
\text { code }\end{array}$} & \multirow{2}{*}{$\begin{array}{l}\text { Zero-order } \\
\mathbf{R}^{2}\end{array}$} & \multirow{2}{*}{$\begin{array}{l}\text { First order } \\
\mathbf{R}^{2}\end{array}$} & \multirow{2}{*}{$\begin{array}{l}\text { Hixon-crowell } \\
\mathbf{R}^{2}\end{array}$} & \multicolumn{2}{|l|}{ Higuchi } & \multicolumn{2}{|c|}{ Korsmeyer peppas } \\
\hline & & & & $\mathbf{R}^{2}$ & $\mathbf{K}$ & $\mathbf{R}^{2}$ & $\mathbf{N}$ \\
\hline F1 & 0.5193 & 0.8267 & 0.7508 & 0.9423 & 25.48 & 0.9951 & 0.28 \\
\hline $\mathrm{F} 2$ & 0.6879 & 0.8185 & 0.7809 & 0.9675 & 15.37 & 0.9785 & 0.31 \\
\hline F3 & 0.9634 & 0.9803 & 0.9760 & 0.9792 & 11.02 & 0.9915 & 0.58 \\
\hline F4 & 0.7957 & 0.9326 & 0.8971 & 0.9927 & 24.6 & 0.9977 & 0.44 \\
\hline F5 & 0.9379 & 0.8988 & 0.9133 & 0.8428 & 9.93 & 0.9532 & 0.97 \\
\hline F6 & 0.9779 & 0.9868 & 0.9847 & 0.9660 & 9.7 & 0.9808 & 0.61 \\
\hline F7 & 0.4234 & 0.7802 & 0.6932 & 0.9264 & 25.3 & 0.9944 & 0.26 \\
\hline F8 & 0.7440 & 0.8509 & 0.8203 & 0.9675 & 14.45 & 0.9504 & 0.31 \\
\hline F9 & 0.9466 & 0.9711 & 0.9640 & 0.9904 & 10.6 & 0.9947 & 0.55 \\
\hline
\end{tabular}


In general, fickian diffusion was used to describe the release of the drug from the matrix tablets. However, in the case of swelling polymers, the release kinetics of the drug did not follow fickian diffusion because the polymer swells and changes volume. In order to describe drug release from swelling polymers, Korsmeyer and Peppas equation called the "power law" was applied. This equation correlates two mechanisms of drug transport that seem independent, fickian diffusion and a case-II transport, thereby describing the release of a drug from a swelling polymer. When $n$ is 0.45 , drug release is diffusion-controlled; when $\mathrm{n}$ is 0.89 , drug release is swelling-controlled. When $\mathrm{n}$ is between 0.45 and 0.89 , release can be defined as a combination of both phenomena. Table 3 shows the values of $\mathrm{n}$ and all of the correlation coefficients for each formulation. In almost all the formulations, higher $\mathrm{R}^{2}$ values suggested that Korsemayer Pappas kinetic model was satisfied. The formulations with lower HPMC concentrations $(20 \%$ and $30 \%)$, value of $\mathrm{n}$ was approximately lower than 0.5 . This suggested that the drug release was erratic and in burst changing the shape of the matrix tablet. When the polymer concentration was increased to $40 \%, \mathrm{n}$ value of Korsemayer Pappas was above 0.55 to 0.61 indicating drug release following nonfickian diffusion that is drug release was both diffusion and swelling controlled.

\section{Search for the optimized formulation of floating matrix tablet}

The criteria for the selection of optimized formulation was primarily based upon the lower values of floating lag time (less than $1 \mathrm{~min}$ ), higher floating time (equal to or more than $22 \mathrm{~h}$ ) and sustained drug release. Based on these criteria, a formulation with 30\% HPMC concentration and $15 \%$ sodium bicarbonate concentration, was selected as optimized formulation.

Fig. 9 indicates an overlay plot and table 4 indicates a comparison of predicted and experimental results. Upon comparison of the observed responses with that of the predicted responses, the percentage error varied between 1.1 to $5.0 \%$. Thus, the low magnitudes of error indicated validation of the experimental design.

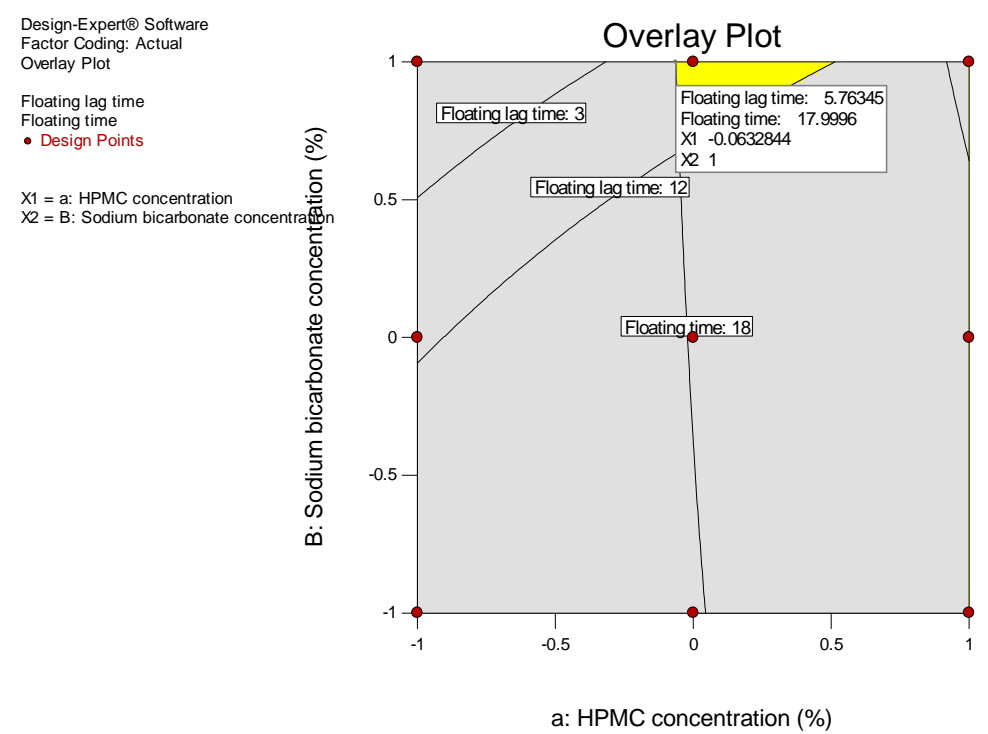

Fig. 9: Overlay plot indicating design space and optimized formulation

Table 4: Comparison of experimental results with predicted responses of formulation

\begin{tabular}{|c|c|c|c|c|c|c|}
\hline \multirow{2}{*}{$\begin{array}{l}\text { Batch } \\
\text { code }\end{array}$} & \multicolumn{2}{|c|}{ Composition } & \multirow[t]{2}{*}{ Response } & \multirow{2}{*}{$\begin{array}{l}\text { Predicted } \\
\text { value }\end{array}$} & \multirow{2}{*}{$\begin{array}{l}\text { Experimental } \\
\text { value }\end{array}$} & \multirow{2}{*}{$\begin{array}{l}\text { Percentage } \\
\text { error }\end{array}$} \\
\hline & $\mathbf{X}_{1}$ & $\mathbf{X}_{2}$ & & & & \\
\hline \multirow{3}{*}{ F8 } & & & Floating lag time & $5.7 \mathrm{sec}$ & $5 \mathrm{sec}$ & $5.0 \%$ \\
\hline & $30 \%$ & $15 \%$ & Floating time & $18 \mathrm{~h}$ & $22 \mathrm{~h}$ & $2.3 \%$ \\
\hline & & & Drug release in $8 \mathrm{~h}$ & $47.9 \%$ & $42.0 \%$ & $1.1 \%$ \\
\hline
\end{tabular}

\section{CONCLUSION}

The floating matrix tablet of clopidogrel bisulphate was successfully designed. The concentration of HPMC and sodium bicarbonate exerted a significant effect on characteristics of the tablet. The optimized formulation resulted in greater floating time and sustained drug release by nonfickian mechanism. Conclusively, a sustained floating matrix tablet of clopidogrel bisulphate was successfully designed by factorial design.

\section{AUTHORS CONTRIBUTIONS}

All the author have contributed equally

\section{CONFLICT OF INTERESTS}

Declared none

\section{REFERENCES}

1. Hou Y, Carrim N, Wang Y, Gallant R, Marshall A, Ni H. Platelets in hemostasis and thrombosis: novel mechanisms of fibrinogen-independent platelet aggregation and fibronectinmediated protein wave of hemostasis. J Biomed Res 2015;29:437-44.

2. Altman R. Risk factors in coronary atherosclerosis atheroinflammation: the meeting point. Thromb J 2003;1:4-4.

3. Bray PF. Platelet hyperreactivity: predictive and intrinsic properties. Hematol/Oncol Clin North Am 2007;21:633-6.

4. Krishnan MN, Zachariah G, Venugopal K, Mohanan PP, Harikrishnan S, Sanjay G, Jeyaseelan L, et al. Prevalence of coronary artery disease and its risk factors in Kerala, south India: a community-based cross-sectional study. BMC Cardiovasc Disord 2016;16:12.

5. Nag T, Ghosh A. Cardiovascular disease risk factors in Asian Indian population: a systematic review. J Cardiovasc Dis Res 2013;4:222-8.

6. Periayah MH, Halim AS, Saad AZ. Mechanism action of platelets and crucial blood coagulation pathways in hemostasis. Int J Hematol Oncol Stem Cell Res 2017;11:319-27. 
7. Sambu N, Curzen N. Monitoring the effectiveness of antiplatelet therapy: opportunities and limitations. Br J Clin Pharmacol 2011;72:683-96.

8. Shifrin MM, Widmar SB. Platelet inhibitors. Nurs Clin North Am 2016;51:29-43.

9. Creager MA. Results of the CAPRIE trial: efficacy and safety of clopidogrel. Clopidogrel versus aspirin in patients at risk of ischaemic events. Vasc Med 1998;3:257-60.

10. Eikelboom JW, Hirsh J, Spencer FA, Baglin TP, Weitz JI. Antiplatelet drugs: antithrombotic therapy and prevention of thrombosis. Chest 2012;141 Suppl 2:e89s-e119s.

11. Huang Z, Francis R, Aubry A, Steckbeck A, Sciascia D. Development of a single in vitro dissolution method for a combination trilayer tablet formulation of clopidogrel and pravastatin. Dissolution Technol 2011;12-9. Doi.org/ 10.14227/DT180111P12

12. Ugurlu T, Rayaman E, Karacicek U. Optimization and evaluation of clarithromycin floating tablets using experimental mixture design. Acta Pol Pharm 2014;71:311-21.

13. Sreejan Manna KJ, Kancherla RA, Lakshmi KK. Alginate-based gastro-retentive raft forming tablets for enhanced bioavailability of Tinidazole. Int J Appl Pharm 2017;9:16-21.

14. Pawar VK, Kansal S, Garg G, Awasthi R, Singodia D, Kulkarni GT. Gastroretentive dosage forms: a review with special emphasis on floating drug delivery systems. Drug Delivery 2011;18:97110.

15. Velivela S, Vinyas M, Pati N. Formulation and in vitro evaluation of Ritonavir floating tablets by melt granulation technique. Int J Appl Pharm 2016;8:12-5.

16. Kumar R, Chandra A. Formulation and evaluation of famotidine micro balloons with enhanced anti-ulcer activity. Int J Appl Pharm 2018;10:131-40.

17. Deshkar SS, Pore AR. Formulation and optimization of immediate release pellets of antiplatelet drugs using the design of experimentation. J Drug Delivery Sci Technol 2017;7:255-68.

18. Gharti KP, Thapa P, Budhathoki U, Bhargava A. Formulation and in vitro evaluation of floating tablets of hydroxypropyl methylcellulose and polyethylene oxide using ranitidine hydrochloride as a model drug. J Young Pharm 2012;4:201-8.

19. Arza RA, Gonugunta CS, Veerareddy PR. Formulation and evaluation of swellable and floating gastroretentive ciprofloxacin hydrochloride tablets. AAPS PharmSciTech 2009;10:220-6.

20. Deshkar S, Pawar M, Shirsat A, Shirolkar S. Development of sustained release tablet of Mebeverine hydrochloride. J Pharm Educ Res 2013;4:64-9.

21. Rao KR, Lakshmi KR. Design, development and evaluation of clopidogrel bisulfate floating tablets. Int J Pharm Investig 2014;4:19-26. 